\title{
Racism and health: The relationship between experience of racial discrimination and health in New Zealand
}

\author{
Ricci Harris $^{\mathrm{a}}$, Martin Tobias ${ }^{\mathrm{b}, *}$, Mona Jeffreys ${ }^{\mathrm{c}}$, Kiri Waldegrave ${ }^{\mathrm{d}}$, \\ Saffron Karlsen ${ }^{\mathrm{e}}$, James Nazroo \\ ${ }^{a}$ Ministry of Health, Wellington, New Zealand \\ ${ }^{\mathrm{b}}$ Ministry of Health, Wellington, New Zealand \\ ${ }^{\mathrm{c}}$ Center for Public Health Research, Massey University, Wellington, New Zealand \\ ${ }^{\mathrm{d}}$ Ministry of Health, Wellington, New Zealand \\ ${ }^{\mathrm{e}}$ Department of Epidemiology and Public Health, International Institute for Society and Health, University College London, UK
}

Available online 5 June 2006

\begin{abstract}
Accumulating research suggests that racism may be a major determinant of health. Here we report associations between self-reported experience of racial discrimination and health in New Zealand.

Data from the 2002/2003 New Zealand Health Survey, a cross-sectional survey involving face-to-face interviews with 12,500 people, were analysed. Five items were included to capture racial discrimination in two dimensions: experience of ethnically motivated attack (physical or verbal), or unfair treatment because of ethnicity (by a health professional, in work or when gaining housing). Ethnicity was classified using self-identification to one of four ethnic groups: Māori, Pacific, Asian and European/Other peoples. Logistic regression, accounting for the survey design, age, sex, ethnicity and deprivation, was used to estimate odds ratios (OR) and 95\% confidence intervals (CI).

Māori reported the highest prevalence of "ever" experiencing any of the forms of racial discrimination (34\%), followed by similar levels among Asian $(28 \%)$ and Pacific peoples $(25 \%)$. Māori were almost 10 times more likely to experience multiple types of discrimination compared to European/Others $(4.5 \%$ vs. $0.5 \%)$.

Reported experience of racial discrimination was associated with each of the measures of health examined. Experience of any one of the five types of discrimination was significantly associated with poor or fair self-rated health; lower physical functioning; lower mental health; smoking; and cardiovascular disease. There was strong evidence of a dose-response relationship between the number of reported types of discrimination and each health measure. These results highlight the need for racism to be considered in efforts to eliminate ethnic inequalities in health.
\end{abstract}

(C) 2006 Elsevier Ltd. All rights reserved.

Keywords: Ethnicity; New Zealand; Racism; Discrimination; Health; Māori

*Corresponding author.

E-mail address: Martin_Tobias@moh.govt.nz (M. Tobias).

\section{Introduction}

There is a growing body of research that suggests that racism may have major health consequences. However, most of this work has been conducted in the US (Krieger, 2000; Williams, Neighbors, \& 
Jackson, 2003; Williams \& Williams-Morris, 2000) and, more recently, in the UK (Karlsen \& Nazroo, 2002, 2004; Karlsen, Nazroo, McKenzie, Bhui, \& Weich, 2005; Nazroo, 2003), with some research in other countries including Canada (Noh \& Kaspar, 2003), the Netherlands (Verkuyten, 1998) and Sweden (Wiking, Johansson, \& Sundquist, 2004). Little is known about the impact of racism on health and ethnic inequalities in other societies, where the history and nature of ethnic relations may be very different. This study examines the association between self-reported experience of racial discrimination and a range of health indicators in New Zealand.

\section{Background}

New Zealand has a population of approximately four million people with the main ethnic groups being European (80\%), Māori (14.7\%), Asian $(6.6 \%)$ and Pacific peoples $(6.5 \%)^{1}$ (Statistics New Zealand, 2002). Māori are the indigenous people and have experienced the effects of European colonisation since the nineteenth century (Durie, 1998; Reid \& Cram, 2005). While small numbers of Pacific and Asian peoples have lived in New Zealand for over 100 years, many are more recent migrants, having arrived in the latter half of the twentieth century (McKinnon, 1996; Statistics New Zealand \& Ministry of Pacific Island Affairs, 2002).

As in other countries with similar histories of colonisation, ethnic inequalities in health exist and, in New Zealand, are most pronounced between Māori and the majority European population (Blakely, Ajwani, Robson, Tobias, \& Bonne', 2004; Bramley, Herbert, Tuzzio, \& Chassin, 2005; Bramley, Hevert, Jackson, \& Chassin, 2004). Māori suffer an eight to nine year lower life expectancy than non-Māori (Statistics New Zealand, 2004) with disparities observed across socioeconomic determinants of health and most mortality and morbidity indicators (including most major chronic diseases, infectious diseases and injuries) (Howden-Chapman \& Tobias, 2000; Ministry of Health, 2004a; Ministry of Social Development, 2004; Statistics New Zealand, 2004). Similar inequalities in measures of socioeconomic and health status are also evident for Pacific peoples living in New Zealand (Ministry of Health, 2004a; Statistics New Zealand \&

\footnotetext{
${ }^{1}$ The percentages sum to more than 100 as people could identify with more than one ethnic group.
}

Ministry of Pacific Island Affairs, 2002), while Asian peoples tend to have similar or better health than European New Zealanders, though there is relatively little information on the health of Asian New Zealanders (Ministry of Health, 2004a).

Internationally, there is increasing acknowledgement of the impact of racism on ethnic inequalities in health, with growing recognition of the need to examine racial discrimination as a social determinant and fundamental driver of such inequalities (Jones, 2001; Krieger, 2003; Nazroo, 2003; Reid \& Robson, 2006; Williams, 1997).

Racism refers to an ideology of superiority, a belief that some races are superior to others (Bhopal, 1998; Williams, 1997). It justifies institutional and individual practices that create and reinforce oppressive systems of race relations and inequality between racial or ethnic groups (Bhopal, 1998; Krieger, 2001), so creating a racialised social order. Racial discrimination (the behavioural or institutional expression of racist ideology) can vary in form and type, depending on how it is expressed, by whom, and against whom (Krieger, 2000). Various forms of racial discrimination have been described with the two main, but not mutually exclusive, types being institutional and interpersonal (Karlsen \& Nazroo, 2002). Interpersonal discrimination refers to discriminatory interactions between individuals, which usually can be directly perceived. Institutional discrimination refers to discriminatory policies or practices embedded in organisational structures and so tends to be more invisible (Karlsen \& Nazroo, 2002; Krieger, 2000).

There are multiple theories explaining how racism may affect health. These include differential exposure to determinants of health (e.g. socioeconomic, environmental and behavioural), differential access to and quality of health services, and the direct effects of racism such as trauma and stress (House \& Williams, 2000; Jones, 2001; Karlsen \& Nazroo, 2002, 2004; Williams, 1997). Similarly, Krieger (2003) identifies five key pathways: (1) economic and social deprivation, (2) exposure to environmental hazards, (3) socially inflicted trauma (directly experienced or witnessed), (4) targeted marketing of harmful products such as tobacco and alcohol, and (5) health care.

A number of studies have found relationships between self-reported experience of racial discrimination and poor health outcomes (Collins, David, Handler, Wall, \& Andes, 2004; Din-Dzietham, Nembhard, Collins, \& Davis, 2004; Karlsen \& 
Nazroo, 2002; Karlsen, et al., 2005; Krieger, 2000; Krieger, Smith, Naishadham, Hartman, \& Barbeau, 2005; Mustillo, Krieger, Gunderson, Sidney, McCreath et al., 2004; Nazroo, 2003; Williams \& Williams-Morris, 2000; Williams et al., 2003). These include relationships with measures of poorer mental health, physical health and health risk behaviours. In addition, some studies have demonstrated associations between measures of institutional discrimination (such as segregation and perceptions of institutional discrimination) and poor health outcomes (Collins, 1999; Jackson, Anderson, Johnson, \& Sorlie, 2000; Karlsen \& Nazroo, 2002; Karlsen et al., 2005; Krieger, 2000; Williams \& Collins, 2001).

Although New Zealand meets international human rights standards in many respects, racial discrimination continues to exist here (Human Rights Commission, 2004; Spoonley, 1993). Evidence of negative attitudes or unfair treatment towards indigenous and ethnic minority groups has been documented in criminal justice (Fergusson, Swain-Campbell, \& Horwood, 2003a, 2003b), education (Bishop, Berryman, Tiakiwai, \& Richardson, 2003), housing (Knight, 1991), and healthcare (Johnstone \& Read, 2000). While racism is recognised as a determinant of health, contributing to ethnic inequalities in New Zealand (Ministry of Health, 2002; Reid \& Robson, 2006), there is no empirical evidence directly examining the relationship between personal experience of racial discrimination and health in this country.

For the first time, the 2002/2003 New Zealand Health Survey (NZHS) included a series of questions on people's experiences of racial discrimination. This study uses data from the NZHS to (i) estimate the prevalence of experience of racial discrimination in specific circumstances in New Zealand, (ii) examine the association of age, sex, deprivation and ethnicity with experience of racial discrimination, and (iii) examine the relationship between experience of racial discrimination and health using a range of health indicators included in the survey.

\section{Methods}

\section{Survey design}

The NZHS used a national stratified sample design. All people aged 15 years and older who were usually resident within permanent private dwellings were eligible for selection. The sampling frame was area-based with small geographic areas of approximately 100 people (meshblocks) comprising the primary sampling units (PSUs). Firstly PSUs were selected. Within selected PSUs, dwellings were then enumerated and sampled. Finally, one eligible person was selected from each sampled dwelling using a Kish grid (Kish, 1949).

To achieve greater statistical power for Māori, Pacific and Asian ethnic groups, a combination of targeting and screening was used in sampling. Based on information from the 2001 Census, PSUs were stratified according to ethnic composition. In order to minimise design effects, dwellings in areas of low Māori, Pacific and Asian density were also screened to identify eligible Māori, Pacific and Asian participants.

Ethics approval was granted for the 2002/2003 NZHS by all regional ethics committees in New Zealand. Data were collected between August 2002 and January 2004 through face-to-face interviews. Additional details on the survey methodology can be found elsewhere (Ministry of Health, 2004b).

\section{Racism variables}

The series of questions on individuals' experience of racial discrimination that were included in the survey were derived from items in the United Kingdom Fourth National Survey of Ethnic Minorities (Modood et al., 1997) and items proposed for the United States 2002 Behavioural Risk Factor Surveillance System (Centers for Disease Control and Prevention (CDC), 2002). This analysis is restricted to the subset of questions asking about individuals' personal experience of racial discrimination, covering five items: experience of ethnically motivated physical or verbal attack; and unfair treatment because of ethnicity by a health professional, in work, or when gaining housing (see Appendix).

To investigate options for variable reduction, exploratory factor analysis was performed in Splus using the correlation matrix with varimax rotation. Because all the variables in the analysis were binary, tetrachoric correlations were computed using Brown's algorithm (Brown, 1977). A two factor solution was found to fit the data well. The first factor loaded high on the three unfair treatment items while the second loaded high on the physical and verbal attack items, suggesting two underlying 
dimensions capturing unfair treatment and personal attack, respectively. Each factor explained equal amounts of variation (29\% and $27 \%$, respectively), with both factors collectively accounting for $56 \%$ of the variation in the data. Therefore, a personal attack subscale was created that combined experience of verbal and/or physical attack into one binary variable. Similarly, an unfair treatment subscale was created combining experience of unfair treatment in any of the three situations asked about (housing, health or work). Finally, all items were grouped together to create an overall discrimination scale capturing experience of racial discrimination in any of the situations asked about. Each subscale and the overall scale classified individuals as either exposed or not exposed based on a positive response to any item within the scale.

Questions on experience of racial discrimination covered two time periods: (1) reported experience of discrimination occurring in the last 12 months; (2) reported experience of discrimination occurring ever in lifetime. The latter is used for most of the analyses presented here, because of small numbers. The only exception is the association between overall discrimination and health for which experience of discrimination in the last 12 months is also presented.

\section{Ethnicity}

The survey used the standard ethnicity question taken from the 2001 Census (Statistics New Zealand, 2001). This question allows people to self-identify with one or more ethnic groups. In this analysis each person is assigned to a single prioritised ethnic group which is standard in New Zealand health research (Ministry of Health, 2004c). Where people identified with more than one ethnic group, priority for ethnicity was given in the following order: Māori, Pacific peoples (includes a number of Pacific ethnic groups), Asian peoples (includes Indian, Chinese and other Asian ethnic groups), European/Others.

The use of ascribed ethnicity (the ethnicity that individuals thought that other people classify them as) was explored in the analysis. However, there were no systematic differences in the prevalence of racism using this classification (data not shown). Therefore, only the results for self-identified prioritised ethnicity are presented here.

\section{Socioeconomic position}

NZDep2001 was used as an indicator of socioeconomic position. This is a census-based small-area index of deprivation that combines (by principal component analysis) nine variables from the 2001 census (i.e. household income, receiving a means tested benefit, access to a car, overcrowding, home ownership, employment status, qualifications, access to a telephone and living in a single parent family) to rank each meshblock (Salmond \& Crampton, 2002). Equivalised household income and personal income were also tested as markers of socioeconomic position and entered into models examining the relationship between discrimination and health, both alone and in combination with each other and NZDep2001. This made little difference to the odds ratios (data not shown) so, as it had the least missing data, only NZDep2001 was retained in the models. NZDep2001 scores were grouped into quintiles for use in this analysis. Higher scores are related to greater deprivation.

\section{Data analysis}

Data were analysed using Stata v8.2 (StataCorp, College Station, TX). To account for the survey design, all analyses were weighted using integrated survey weights to produce estimates representative of the New Zealand population. Survey weights were unique to each respondent, and adjusted for an individual's probability of selection and differential non-response.

\section{Prevalence}

Crude prevalence estimates of self-reported experience of discrimination were calculated for each ethnic group. Logistic regression was used to examine the independent association of age (15-24, 25-44, 45-64, 65+ years), sex (male, female), socioeconomic position (NZDep2001 quintiles, $1=$ least deprived to $5=$ most deprived) and ethnicity (Māori, Pacific peoples, Asian peoples, European/Others) with reporting of racial discrimination. In order to capture possible differences in the extent of exposure to racial discrimination, prevalence of reporting experience of racial discrimination to none, one, two and three or more items was examined for each ethnic group.

\section{Association with health}

Logistic regression was performed to examine the relationship between experience of discrimination 
(items, sub-scales, scale) and five different indicators of health. The indicators of health were chosen based on the quality of the measures and the use of related health indicators in similar research internationally (Karlsen \& Nazroo, 2002; Williams et al., 2003). The selected health indicators were self-rated health (poor or fair), physical functioning (lowest quartile of SF36 physical functioning scale, Ware, Kosinski, \& Gandek, 1993), mental health (lowest quartile of the SF36 mental health scale), current smoking (one or more cigarettes a day), and selfreported cardiovascular disease (CVD, including heart disease and stroke). In the models we adjusted for age, sex, NZDep2001 and ethnicity as described above. Analyses of CVD were restricted to those participants aged 25 years and over. Adjusted odds ratios are presented that show the odds of the health outcome among people who were exposed to discrimination compared to those who were not. In addition, the relationship between responses to multiple discrimination items and health indicators was also examined.

\section{Interactions and stratified analyses}

We hypothesised that there may be differences in the association between experience of racial discrimination and health by ethnic group and deprivation quintile. Therefore, we tested for multiplicative statistical interaction between every discrimination variable and each of ethnicity and deprivation for all health outcome indicators. This resulted in 80 interaction tests, three of which had a $p$-value $<0.01$. Given that the large number of tests done are likely to produce some spurious associations, we concluded that there were no important interactions. In addition, stratified analyses showed similar associations between racial discrimination measures and health indicators in each ethnic group (data not shown). Therefore, all ethnic groups were combined to examine associations between discrimination and health measures.

\section{Tests for trend}

Tests for trend were estimated using adjusted Wald tests.

\section{Results}

The survey achieved a $72 \%$ response rate overall (Ministry of Health, 2004b), comprising 70\% among Māori, 60\% among Pacific, 62\% among Asian and $77 \%$ among European/Other partici- pants. Twenty nine people were excluded from all analyses because of missing values for NZDep2001. The dataset used in these analyses consisted of 12,500 people, of whom 4108 were Māori, $900 \mathrm{~Pa}-$ cific people, 1169 Asian people and 6323 European/ Others. Europeans $(n=6269)$ made up $99.1 \%$ of the European/Other group.

Table 1 shows unadjusted prevalences of selfreported experience of discrimination by ethnicity, both 'ever' and in the last 12 months, for each item, subscale and scale. As expected, experience of racial discrimination was higher among non-European ethnic groups. For all ethnic groups, the most common experience of racial discrimination was verbal attack. Māori reported the highest prevalence of being a victim of an ethnically motivated physical attack (8.5\% 'ever'). Māori, Pacific and Asian peoples all report higher levels of unfair treatment ('ever') in healthcare, housing and work. Amongst European/Others, the most common experience of unfair treatment was in the context of work $(2.2 \%)$. A subanalysis showed that this was mainly due to a relatively higher prevalence among 'Others' $(n=54)$ and Europeans born outside New Zealand $(n=1103)(4.9 \%, 95 \%$ CI $3.4-6.4)$.

Reported experience of any of the discrimination items (overall discrimination) 'ever' is over twice as high in Māori compared with European/Others $(34 \%$ vs. $14.6 \%)$. Pacific and Asian peoples are intermediate with almost $25 \%$ of Pacific and $28 \%$ of Asian peoples reporting having 'ever' experienced any of the forms of racial discrimination. While overall discrimination 'ever' was highest amongst Māori, prevalence in the 'last 12 months' was similar, and highest, for both Māori and Asian.

While the subscales and overall discrimination scale allow comparisons between ethnic groups using summary measures, they do not distinguish between those people who report experience of discrimination to one item only and those who report experience of discrimination to multiple items (i.e. answer positively to more than one question). These measures therefore underestimate the experience of discrimination for those groups more likely to experience multiple types of discrimination. This is the case for Māori in particular, and Asian and Pacific peoples to a lesser extent (Table 2). Māori are almost 10 times more likely to experience multiple (three or more) types of discrimination than European/Others.

Table 3 shows the independent association of age, sex, deprivation and ethnicity with reported 
Table 1

Prevalence of self-reported exposure to racial discrimination (ever and in the last 12 months) by ethnic group

\begin{tabular}{|c|c|c|c|c|c|}
\hline Racism variable & & Māori & Pacific & Asian & European/Others ${ }^{\mathrm{a}}$ \\
\hline \multirow[t]{11}{*}{ Ever } & Items & & & & \\
\hline & Physical attack & $8.5 \%(6.6-10.3)$ & $2.3 \%(1.2-3.3)$ & $2.9 \%(1.4-4.3)$ & $3.3 \%(2.8-3.9)$ \\
\hline & Verbal attack & $24.5 \%(21.6-27.3)$ & $12.6 \%(9.4-15.9)$ & $19.7 \%(16.2-23.2)$ & $10.4 \%(9.5-11.3)$ \\
\hline & Unfair treatment & & & & \\
\hline & Health & $4.5 \%(3.2-5.8)$ & $5.8 \%(3.5-8.1)$ & $2.1 \%(0.9-3.2)$ & $1.4 \%(1.1-1.8)$ \\
\hline & Work & $5.6 \%(4.1-7.1)$ & $8.2 \%(5.2-11.3)$ & $7.8 \%(5.5-10.1)$ & $2.2 \%(1.7-2.6)$ \\
\hline & Housing & $9.5 \%(7.6-11.5)$ & $6.3 \%(4.1-8.5)$ & $4.1 \%(2.2-6.0)$ & $0.7 \%(0.5-1.0)$ \\
\hline & Scales & & & & \\
\hline & Any personal attack & $27.1 \%(24.2-30.1)$ & $13.3 \%(10.1-16.6)$ & $21.2 \%(17.6-24.8)$ & $12.3 \%(11.3-13.2)$ \\
\hline & Any unfair treatment & $15.9 \%(13.5-18.3)$ & $15.8 \%(12.1-19.5)$ & $12.2 \%(9.3-15.2)$ & $4.0 \%(3.4-4.6)$ \\
\hline & Overall discrimination $^{\mathrm{b}}$ & $34.0 \%(30.9-37.1)$ & $24.5 \%(20.3-28.7)$ & $27.9 \%(24.0-31.9)$ & $14.6 \%(13.5-15.6)$ \\
\hline \multirow[t]{11}{*}{ Last 12 months } & Items & & & & \\
\hline & Physical attack & $3.3 \%(0.7-4.6)$ & $1.4 \%(0.5-2.3)$ & $1.9 \%(0.7-3.1)$ & $0.9 \%(0.5-1.2)$ \\
\hline & Verbal attack & $11.3 \%(9.1-13.5)$ & $3.5 \%(1.9-5.1)$ & $12.3 \%(9.3-15.2)$ & $3.7 \%(3.1-4.2)$ \\
\hline & Unfair treatment & & & & \\
\hline & Health & $2.0 \%(1.2-2.8)$ & $1.9 \%(0.8-3.0)$ & $1.3 \%(0.5-2.1)$ & $0.6 \%(0.3-0.8)$ \\
\hline & Work & $1.7 \%(0.9-2.5)$ & $2.7 \%(1.1-4.2)$ & $4.3 \%(2.5-6.1)$ & $0.7 \%(0.5-1.0)$ \\
\hline & Housing & $2.2 \%(1.4-3.1)$ & $1.7 \%(0.5-2.9)$ & $2.6 \%(1.0-4.1)$ & $0.1 \%(0.0-0.2)$ \\
\hline & Scales & & & & \\
\hline & Any personal attack & $12.4 \%(10.1-14.7)$ & $4.2 \%(2.5-5.9)$ & $13.3 \%(10.2-16.4)$ & $4.1 \%(3.4-4.7)$ \\
\hline & Any unfair treatment & $5.1 \%(3.8-6.4)$ & $5.3 \%(3.2-7.3)$ & $7.1 \%(4.8-9.4)$ & $1.3 \%(1.0-1.6)$ \\
\hline & Overall discrimination $^{\mathrm{b}}$ & $15.3 \%(12.9-17.8)$ & $8.6 \%(6.1-11.2)$ & $17.3 \%(13.9-20.8)$ & $4.8 \%(4.2-5.5)$ \\
\hline
\end{tabular}

${ }^{\mathrm{a}}$ Includes all non-Māori, non-Pacific, non-Asian.

${ }^{\mathrm{b}}$ Positive response to any racial discrimination item.

Table 2

Levels of self-reported exposure to any racial discrimination item 'ever' by ethnic group

\begin{tabular}{lllll}
\hline Level $^{\mathrm{a}}$ & Māori & Pacific & Asian & European/Others $^{\mathrm{b}}$ \\
\hline Reports 1 only & $21.1 \%(18.5-23.8)$ & $17.2 \%(13.6-20.9)$ & $21.1 \%(17.5-24.8)$ & $11.6 \%(10.7-12.6)$ \\
Reports 2 only & $8.3 \%(6.4-10.2)$ & $4.4 \%(2.3-6.5)$ & $5.2 \%(3.2-7.2)$ & $2.5 \%(2.0-3.0)$ \\
Reports 3 or more & $4.5 \%(3.2-5.9)$ & $2.8 \%(1.2-4.5)$ & $1.6 \%(0.6-2.5)$ & $0.5 \%(0.3-0.7)$ \\
\hline
\end{tabular}

${ }^{a}$ Number of discrimination items to which respondents reported exposure.

${ }^{\mathrm{b}}$ Includes all non-Māori, non-Pacific, non-Asian.

experience of racial discrimination. These analyses demonstrate that, after adjusting for the other variables in model, personal attacks (both physical and verbal) are most common in young men whereas reporting of unfair treatment by a health professional is more common in women. There also appears to be a weak association between experience of discrimination and deprivation. This was significant for verbal attack and unfair treatment by a health professional, with increasing deprivation being associated with increasing prevalence of discrimination. The like- lihood of reporting experience of an ethnically motivated personal attack in particular, decreased with increasing age.

Table 4 shows the association between experience of racial discrimination and health outcomes. The results suggest that reported experience of racial discrimination is associated with poorer health and with current smoking for each of the measures examined. This is independent of the effect of age, sex, ethnicity and deprivation; adjustment for these variables made little difference to the odds ratios (data not shown). 


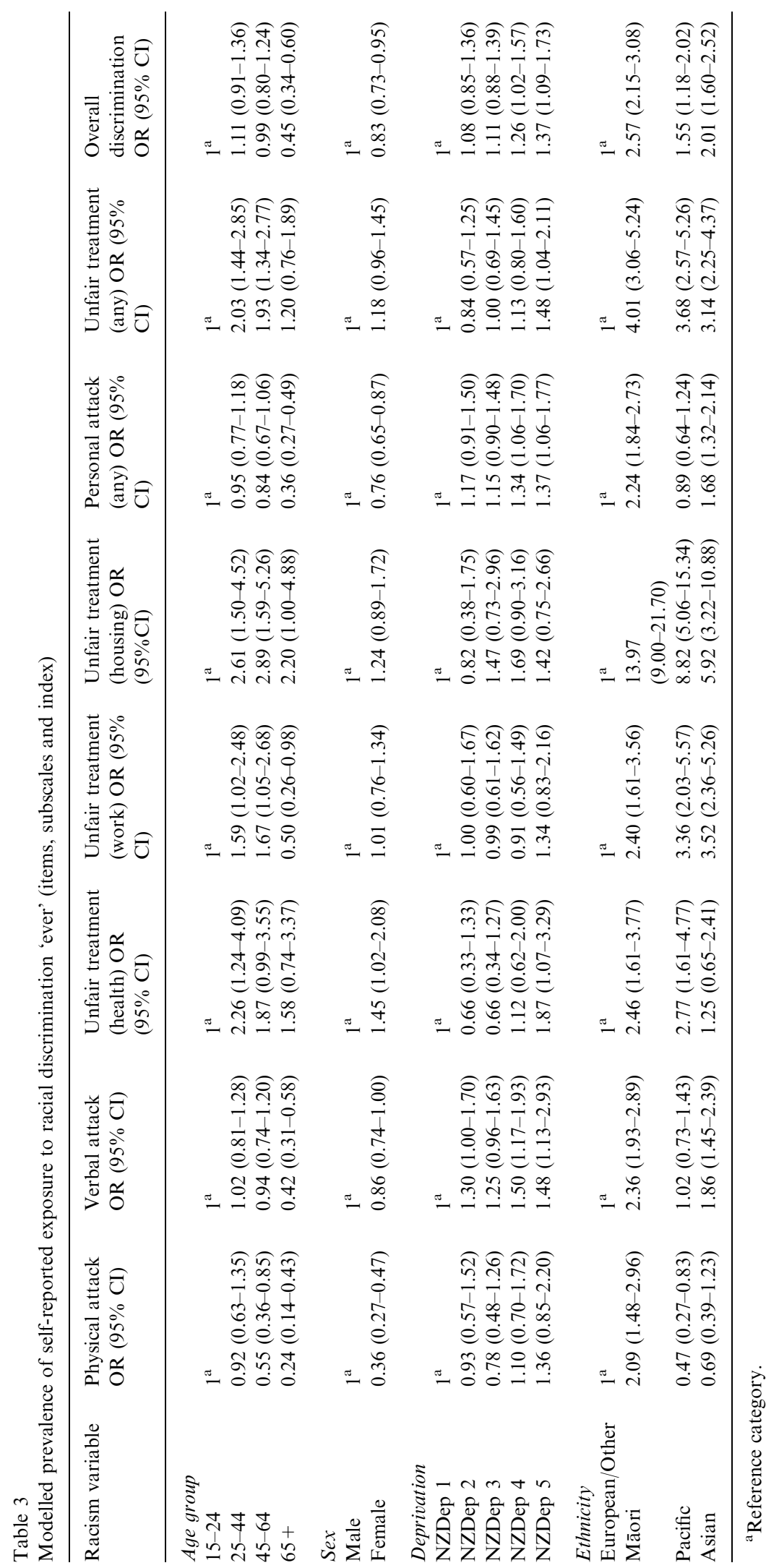




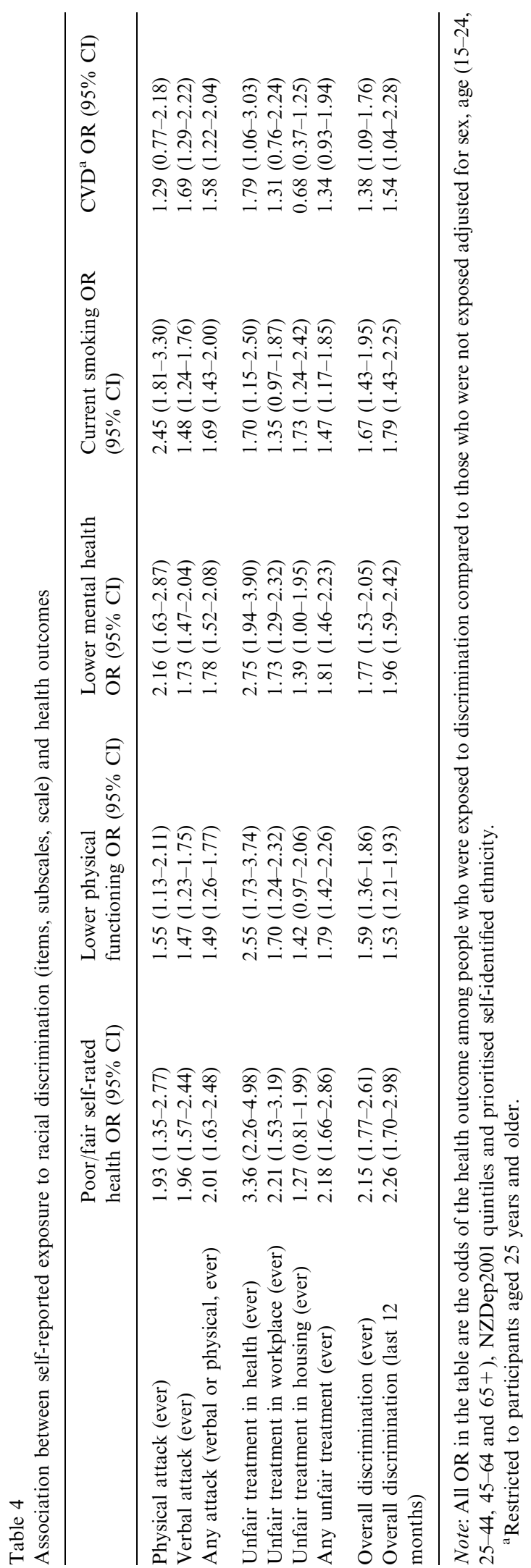

We also tested whether smoking was acting as a mediator of the effect of experience of discrimination on negative health outcomes. After adjusting for smoking in three categories (never, ex-smoker, current smoker), we found that measures of discrimination remained strongly associated with poor/fair self-rated health, lower physical functioning, lower mental health and CVD (data not shown).

The model also shows a dose-response relationship between the number of reported types of discrimination and all of the health measures examined (Table 5). Respondents who report experiencing to three or more types of discrimination are up to three times more likely to report adverse health outcomes than those who do not report any discrimination.

\section{Discussion}

To our knowledge, this is the first New Zealand study to examine people's self-reported experiences of racial discrimination and its relationship to health. The findings show that racial discrimination (as measured) in New Zealand is disproportionately experienced by non-European ethnic groups, particularly Māori. Furthermore, self-reported experience of discrimination is strongly associated with various measures of poor health for all ethnic groups, independent of the effect of socioeconomic position. Given these findings, experience of racial discrimination may be a potentially major health risk that contributes significantly to ethnic inequalities in health in New Zealand, as elsewhere (House \& Williams, 2000; Nazroo, 2003).

A strength of our work is that for the first time in New Zealand, we have estimated the prevalence and shown the association with health of self-reported discrimination in different ethnic groups, in a national sample. This provides not only a benchmark for future work, but also an indication that racial discrimination is an important factor in determining health status in New Zealand, as it appears to be in other studies with different historical contexts.

However, a number of limitations need to be considered in the interpretation of these findings. Our study allows the examination of respondents' self-reported experience of racial discrimination in multiple situations, over two time intervals (last 12 months and 'ever') and in different forms. Karlsen and Nazroo (2002) note the difficulties associated 
Table 5

Association between multiple reported exposures to racial discrimination 'ever' and health outcomes

\begin{tabular}{|c|c|c|c|c|c|}
\hline & $\begin{array}{l}\text { Poor/fair self-rated } \\
\text { health OR }(95 \% \\
\text { CI) }\end{array}$ & $\begin{array}{l}\text { Lower physical } \\
\text { functioning OR } \\
(95 \% \mathrm{CI})\end{array}$ & $\begin{array}{l}\text { Lower mental } \\
\text { health OR }(95 \% \\
\text { CI) }\end{array}$ & $\begin{array}{l}\text { Current smoking } \\
\text { OR }(95 \% \mathrm{CI})\end{array}$ & $\begin{array}{l}\text { CVD }^{\mathrm{a}} \text { OR }(95 \% \\
\mathrm{CI})\end{array}$ \\
\hline \multicolumn{6}{|l|}{$\begin{array}{l}\text { Overall racism (any } \\
\text { exposure) }\end{array}$} \\
\hline Any vs. none & $2.15(1.77-2.61)$ & $1.59(1.36-1.86)$ & $1.77(1.53-2.05)$ & $1.67(1.43-1.95)$ & $1.38(1.09-1.76)$ \\
\hline \multicolumn{6}{|l|}{ Positive response to } \\
\hline One Q vs. none & $2.02(1.63-2.52)$ & $1.48(1.24-1.76)$ & $1.56(1.32-1.84)$ & $1.61(1.35-1.92)$ & $1.17(0.89-1.54)$ \\
\hline Two Qs vs. none & $2.26(1.54-3.32)$ & $1.91(1.39-2.62)$ & $2.47(1.86-3.28)$ & $1.59(1.16-2.18)$ & $2.36(1.48-3.76)$ \\
\hline $\begin{array}{l}\text { Three or more Qs vs. } \\
\text { none }\end{array}$ & $3.60(2.13-6.10)$ & $2.15(1.35-3.44)$ & $2.95(1.84-4.74)$ & $2.93(1.80-4.77)$ & $1.41(0.57-3.51)$ \\
\hline$p$ (trend) & $<0.001$ & $<0.001$ & $<0.001$ & $<0.001$ & 0.003 \\
\hline
\end{tabular}

Note: Adjusted for sex, age (15-24, 25-44, 45-64 and 65+), NZDep quintiles and prioritised self-identified ethnicity.

${ }^{\mathrm{a}}$ Restricted to participants aged 25 years and older.

with measuring the extent to which individuals experience racism. Our measures of racial discrimination are unable to determine the exact nature or intensity of the experience and whether these were different for different groups. In addition, we have limited capacity to assess the frequency of exposure over time. These issues impact on our capacity to assess exposure to acute and cumulative racism that may have important effects on different health outcomes (Krieger, 2000). In addition, there are a number of situations where people may experience discrimination that we did not ask about, for example at school, in shops and on the street.

The measures of racial discrimination in this study largely reflect experiences of interpersonal discrimination. As Krieger (2000) notes, these interactions only cover one of several forms of discrimination that can affect peoples lives. Racism must be understood in its larger social context (Jackson et al., 1996). Importantly, the racial discrimination questions analysed in this study do not capture institutional racism well, although the measure of socioeconomic position included in our study (deprivation) does indirectly capture the major pathway through which institutional racism acts. This form of racism is arguably the most powerful in determining ethnic inequalities in health (Jones, 2000; Williams, 1997). Krieger (2000, p. 41) also notes that, "discrimination is a socially structured and sanctioned phenomenon ... intended to maintain privileges for members of dominant groups at the cost of deprivation for others". Our measures tap an important component of racial discrimination and identify differences between ethnic groups. However, they do not fully reflect the underlying inequalities in power that result in privilege and disadvantage at a structural level, and may therefore underestimate experience of racism (in its broader sense) particularly for more socially disadvantaged ethnic groups, including Māori, Pacific and Asian peoples.

Asking about experience of discrimination is inherently subjective, with the same issues of validity that apply to any self-reported exposure (Krieger, 2000). Experience of discrimination may be underestimated if people choose not to disclose this information. In a British study, participants were reluctant to discuss their experiences of discrimination, initially denying that they had experienced racial harassment, but later discussing such experiences in depth (Chahal \& Julienne, 1999). Furthermore, people's interpretations and responses to the "objective" experience may vary (Karlsen \& Nazroo, 2002). For example, "internalised racism," where negative messages become accepted by members of racialised groups (Jones, 2001) may result in differential reporting of experiences of discrimination to the same "exposure," with instances of unfair treatment potentially viewed as "deserved" and non-discriminatory (Krieger, 2000). People may also provide "socially acceptable" responses or exaggerate experiences of discrimination (Krieger, 2000). While surveys from the UK show that around $13 \%$ of people from ethnic minority groups report experiencing some form of racial harassment each year (Virdee, 1997), qualitative evidence suggests that this may be an underestimate (Chahal \& Julienne, 1999; Virdee, 1997). 
"Personal/group discrimination discrepancy," whereby people tend to report perceiving greater discrimination directed toward their group than toward themselves personally, may have affected our results (Krieger, 2000; Taylor, Wright, Maghaddam, \& Lalonde, 1990). For example, people may recognise patterns of discrimination not readily discerned by personal experience (Krieger, 2000; Taylor et al., 1990). This may be the case with unfair treatment within institutional settings, as it often requires knowledge of how others are treated (Krieger, 2000) and, in settings such as health, technical knowledge of appropriate care. Furthermore, exposure to discrimination may be influenced by period and cohort effects (Krieger, 2000). For example, in the US, although overt discrimination is becoming less apparent (National Research Council, 2004), discrimination persists in more subtle forms that are more difficult to recognise and measure. For all the above reasons, under-reporting of experiences of discrimination may have occurred in our study. Although non-differential underreporting will lead to underestimation of the association between discrimination and health, differential under-reporting of experiences of discrimination cannot be excluded.

To enable stable estimates, we describe selfreported discrimination among four ethnic group categories. However, we acknowledge the diversity within these categories, some of which include multiple ethnicities. In particular, the European/ Other group includes 54 people of non-European ethnicity. The latter group is likely to be very different from the European ethnic group, although their small numbers mean that the results shown for the European/Other group reflect those reported by Europeans $(n=6269)$.

Our estimates of the associations of health measures with experience of discrimination may be subject to residual confounding. For example, the strongest association with all measures of health were seen with reporting of unfair treatment by a health professional. While differential quality of care is one of the mechanisms through which the impact of racism on health is thought to operate (Jones, 2001), poor health itself is also related to frequency of encounter with a health professional, something for which we were unable to fully adjust.

Precise comparisons with other studies are difficult due to varying measures of racial discrimination and health indicators, as well as different study populations. The UK Fourth National Survey of Ethnic Minorities (Virdee, 1997) shows similar prevalences of experiences of personal attack between ethnic minorities in the UK to our findings for Māori and Asian peoples in New Zealand. Thirteen percent of ethnic minorities in the UK reported experiencing racially motivated physical or verbal attacks in the previous 12 months, compared with $12 \%$ of Māori and $13 \%$ of Asian peoples in New Zealand. As with the current study, in the UK verbal attack was more common than physical and both were more common in young males. Discrimination in the workplace was higher among UK ethnic minority groups, with $19 \%$ of ethnic minorities reporting being refused a job in the previous 12 months, although this was for perceived religious as well as ethnic reasons (Modood et al., 1997). In our study, Asian peoples reported the highest prevalence of discrimination in the work setting, at $4.3 \%$ in the last 12 months. In a US study (Laveist, Rolley, \& Diala, 2003), 3.9\% of African American participants, $3.1 \%$ of Hispanic and $0.4 \%$ of whites reported being discriminated against within the health care system because of their race. This compares to $2 \%$ of Māori and Pacific peoples, $1.3 \%$ of Asian and $0.6 \%$ of European/Others who reported unfair treatment by a health professional because of their ethnicity in our study. Some US studies have found much higher prevalences of racism, such as that by Krieger, Sidney, and Coakley (1998), where $80 \%$ of "Black" respondents reported ever experiencing racial discrimination. While our analysis is not directly comparable to that of Krieger and colleagues', there may be a number of measurement issues that lead to the underestimation of experience of racism in our study, as discussed above.

In our study, a strong independent association remained between experience of discrimination and negative health measures after data were adjusted for socioeconomic position. However, socioeconomic inequality between ethnic groups is in itself thought to be, in part, the result of institutional racism (Jones, 2001; Krieger, 2000; Williams, 1997). Our analyses therefore, suggest that interpersonal and institutional racism (the latter mediated partly through socioeconomic position) may have independent effects on health.

The most commonly examined association between self-reported discrimination and health has been with poorer mental health outcomes, where consistent relationships are found (Gee, 2002; 
Karlsen \& Nazroo, 2002; Karlsen et al., 2005; Roberts, Swanson, \& Murphy, 2004; Williams et al., 2003). Associations between self-reported discrimination and negative physical health outcomes and health behaviours have also been detected (Williams et al., 2003). Related to our study are associations with poorer self-rated health (Karlsen \& Nazroo, 2002), and measures related to CVD such as hypertension (Din-Dzietham et al., 2004; Guyll, Matthews, \& Bromberger, 2001; Krieger \& Sidney, 1996; Steffen, McNeilly, Anderson, \& Sherwood, 2003), and cigarette smoking (Guthrie, Young, Williams, Boyd, \& Kintner, 2002; Krieger et al., 2005; Landrine \& Klonoff, 1996).

In a recent review of community studies examining self-reported experience of racial discrimination and health status, Williams et al. (2003) note that it is not clear whether there is a dose-response relationship between discrimination and changes in health status, with some studies finding nonlinear patterns in the association between perceived discrimination and blood pressure (Krieger, 1990; Krieger \& Sidney, 1996). Using multiple experiences of discrimination in different situations as a proxy measure of dose, our findings show a dose-response relationship between experience of discrimination and negative health measures. While cross-sectional studies are limited in their ability to attribute causation, the dose-response relationship that we observed is at least consistent with a causal association.

The fact that people are subjected to racial discrimination is an unacceptable breach of human rights, and an issue New Zealand, and other societies, must address. The many different types, forms, levels and expressions of racism (Krieger, 2000) will require different policy approaches. This study demonstrates that self-reported experience of racial discrimination is strongly associated with a range of negative health outcomes and with tobacco use among New Zealand adults. The higher risk of exposure among Māori, Asian and Pacific peoples indicates that any negative health outcomes will disproportionately impact on these groups. This study lends support to the growing body of evidence that racism is a major determinant of health and a driver of ethnic inequalities in health. As such, policies designed to address racism should be included in the strategies adopted by governments to eliminate ethnic inequalities in health. This needs to involve both the health sector and wider society.

\section{Acknowledgements}

We would like to acknowledge the participants of the 2002/2003 New Zealand Health Survey. We would also like to thank Sue Paul and Karen Blakey for assistance with initial analyses and psychometric testing. The 2002/2003 New Zealand Health Survey was funded by the New Zealand Ministry of Health. The Centre for Public Health Research, Massey University, is supported by a programme grant from the Health Research Council of New Zealand. Disclaimer Ricci Harris, Martin Tobias and Kiri Waldegrave are employees of the New Zealand Ministry of Health. The views expressed in this paper are the authors' own and do not necessarily represent the views or policy advice of the Ministry of Health. The paper was submitted for publication with the permission of the Deputy Director General-Public Health.

\section{Appendix}

Racial discrimination questions from the 2002/ 2003 New Zealand Health Survey

Question

Q 270. Have you ever been the victim of an ethnically motivated attack (verbal or physical abuse to the person or property) in New Zealand?

Q 271. Have you ever been treated unfairly (e.g. treated differently, kept waiting) by a health professional (e.g. doctor, nurse, dentist etc.) because of your ethnicity in New

Zealand? Q 272. Have you ever been treated unfairly at work or been refused a
Response options

Yes, verbal-within the past 12 months

Yes, verbal-more than 12 months ago Yes, physical - within the past 12 months Yes, physical-more than 12 months ago No

Don't know/unsure Refuse

Yes, within the past 12 months Yes, more than 12 months ago

No

Don't know/unsure Refuse 
job because of your

ethnicity in New

Zealand?

Q 273. Have your ever

been treated unfairly

when renting or buying

housing because of your

ethnicity in New

Zealand?

\section{References}

Bhopal, R. (1998). Spectre of racism in health and health care: Lessons from history and the United States. British Medical Journal, 316, 1970-1973.

Bishop, R., Berryman, M., Tiakiwai, S., \& Richardson, C. (2003). Te Kötahitanga: The experiences of year 9 and 10 Māori students in mainstream classrooms. Wellington: Ministry of Education.

Blakely, T., Ajwani, S., Robson, B., Tobias, M., \& Bonne', M. (2004). Decades of disparity: Widening ethnic mortality gaps from 1980 to 1999. New Zealand Medical Journal, 117(1199).

Bramley, D., Herbert, P., Tuzzio, L., \& Chassin, M. (2005). Disparities in indigenous health: A cross-country comparison between New Zealand and the United States. American Journal of Public Health, 95(5), 844-850.

Bramley, D., Hevert, P., Jackson, R., \& Chassin, M. (2004). Indigenous disparities in disease-specific mortality, a cross-country comparison: New Zealand, Australia, Canada, and the United States. New Zealand Medical Journal, 117(1207).

Brown, M. B. (1977). Algorithm AS 116: The tetrachoric correlation and its standard error. Applied Statistics, 26, 343-351.

Centers for Disease Control and Prevention (CDC). (2002). Behavioural risk factor surveillance system survey questions. Atlanta, Georgia: U.S. Department of Health and Human Services, Centers for Disease Control and Prevention.

Chahal, K., \& Julienne, L. (1999). “We can't all be white!' Racist victimisation in the UK. London, England: York Publishing Services.

Collins, C. A. (1999). Racism and health: Segregation and causes of death amenable to medical intervention in major U.S. cities. Annals of the New York Academy of Sciences, 896, 396-398.

Collins, J. W. C., David, R. J., Handler, A., Wall, S., \& Andes, S. (2004). Very low birthweight in African American infants: The role of maternal exposure to interpersonal racial discrimination. American Journal of Public Health, 94(12), 2132-2138.

Din-Dzietham, R., Nembhard, W. N., Collins, R. C., \& Davis, S. K. (2004). Perceived stress following raced-based discrimination at work is associated with hypertension in AfricanAmericans. The metro Atlanta heart disease study. Social Science and Medicine, 58, 449-461.
Durie, M. (1998). Whaiora: Māori health development (2nd ed.). Auckland: Oxford University Press.

Fergusson, D., Swain-Campbell, N., \& Horwood, L. (2003a). Arrests and convictions for cannabis related offences in a New Zealand birth cohort. Drug and Alcohol Dependence, 70(1), 53-63.

Fergusson, D., Swain-Campbell, N., \& Horwood, L. (2003b). Ethnicity and criminal convictions: Results of a 21 year longitudinal study. The Australian and New Zealand Journal of Criminology, 36(3), 354-367.

Gee, G. C. (2002). A multilevel analysis of the relationship between institutional and individual racial discrimination and health status. American Journal of Public Health, 92(4), 615-623.

Guthrie, B. J., Young, A. M., Williams, D. R., Boyd, C. J., \& Kintner (2002). African American girls' smoking habits and day-to-day experiences with racial discrimination. Nursing Research, 51(3), 183-190.

Guyll, M., Matthews, K. A., \& Bromberger, J. T. (2001). Discrimination and unfair treatment: relationship to cardiovascular reactivity among African American and European American women. Health Psychology, 20(5), 315-325.

House, J. S., \& Williams, D. R. (2000). Understanding and reducing socioeconomic and racial/ethnic disparities in health. In B. Smedley, \& S.L. Syme (Eds.), Promoting health: Intervention strategies from social and behavioural research (pp. 81-124). Washington, DC: The National Academies Press.

Howden-Chapman, P., \& Tobias, M. (2000). Social inequalities in health: New Zealand 1999. Wellington: Ministry of Health.

Human Rights Commission. (2004). Human rights in New Zealand today. Wellington: Human Rights Commission.

Jackson, J. S., Brown, T. N., Williams, D. R., Torres, M., Sellers, S. L., \& Brown, K. (1996). Racism and the physical and mental health status of African Americans: A thirteen year national panel study. Ethnicity and Disease, 6, 132-147.

Jackson, S. A., Anderson, R. T., Johnson, N. J., \& Sorlie, P. D. (2000). The relation of residential segregation to all-cause mortality: A study in Black and White. American Journal of Public Health, 90(4), 615-617.

Johnstone, K., \& Read, J. (2000). Psychiatrists' recommendations for improving bicultural training and Maori mental health services: A New Zealand survey. Australian and New Zealand Journal of Psychiatry, 34, 135-145.

Jones, C. P. (2000). Levels of racism: A theoretic framework and a gardener's tale. American Journal of Public Health, 90(8), 1212-1215.

Jones, C. P. (2001). Invited commentary: "Race," racism, and the practice of epidemiology. American Journal of Epidemiology, 154(4), 299-304.

Karlsen, S., \& Nazroo, J. Y. (2002). Relation between racial discrimination, social class, and health among ethnic minority groups. American Journal of Public Health, 92(4), 624-630.

Karlsen, S., \& Nazroo, J. Y. (2004). Fear of racism and health. Journal of Epidemiology and Community Health, 58, 1017-1018.

Karlsen, S., Nazroo, J. Y., McKenzie, K., Bhui, K., \& Weich, S. (2005). Racism, psychosis and common mental disorder among ethnic minority groups in England. Psychological Medicine, 35(12), 1795-1803. 
Kish, L. (1949). A procedure for objective respondent selection within the household. Journal of the American Statistical Association, 44, 380-387.

Knight, S. (1991). No longer available: A study of racial discrimination and private rental accommodation. Auckland: Race Relations Office.

Krieger, N. (1990). Racial and gender discrimination: Risk factors for high blood pressure? Social Science and Medicine, 30(12), 1273-1281.

Krieger, N. (2000). Discrimination and health. In L. Berkman, \& I. Kawachi (Eds.), Social epidemiology (pp. 36-75). New York: Oxford University Press.

Krieger, N. (2001). A glossary for social epidemiology. Journal of Epidemiology and Community Health, 55, 693-700.

Krieger, N. (2003). Does racism harm health? Did child abuse exist before 1962? On explicit questions critical science and current controversies: An ecosocial perspective. American Journal of Public Health, 93(2), 194-199.

Krieger, N., \& Sidney, S. (1996). Racial discrimination and blood pressure: The CARDIA study of young black and white adults. American Journal of Public Health, 86, 1370-1378.

Krieger, N., Sidney, S., \& Coakley, E. (1998). Racial discrimination and skin color in the CARDIA study: Implications for public health research. American Journal of Public Health, 88(9), 1308-1378.

Krieger, N., Smith, K., Naishadham, D., Hartman, C., \& Barbeau, E. M. B. (2005). Experiences of discrimination: Validity and reliability of a self-report measure for population health research on racism and health. Social Science and Medicine, 61, 1576-1596.

Landrine, H., \& Klonoff, E. A. (1996). The schedule of racist events: A measure of racial discrimination and a study of its negative physical and mental health consequences. Journal of Black Psychology, 22(2), 144-168.

Laveist, T. A., Rolley, N. C., \& Diala, C. (2003). Prevalence and patterns of discrimination among U.S. health care consumers. International Journal of Health Services, 33(2), 331-344.

McKinnon, M. W. (1996). Immigrants and citizens: New Zealanders and Asian immigration in historical context. Wellington: Victoria University of Wellington Press.

Ministry of Health. (2002). Reducing inequalities in health. Wellington: Ministry of Health.

Ministry of Health. (2004a). An indication of New Zealanders' health 2004. Wellington: Ministry of Health.

Ministry of Health. (2004b). A portrait of health: Key results of the 2002/03 New Zealand health survey. Wellington: Ministry of Health.

Ministry of Health. (2004c). Ethnicity data protocols for the health and disability sector. Wellington: Ministry of Health.

Ministry of Social Development. (2004). The social report 2004. Wellington: Ministry of Social Development.

Modood, T., Berthoud, R., Lakey, J., Nazroo, J., Smith, P., Virdee, S., et al. (1997). Ethnic minorities in Britain: Diversity and disadvantage. London: Policy Studies Institute.

Mustillo, S., Krieger, N., Gunderson, E. P., Sidney, S., McCreath, H., \& Kiefe, C. I. (2004). Self-reported experiences of racial discrimination and Black-White difference in preterm and low-birthweight deliveries: The CARDIA study. American Journal of Public Health, 94(12), 2125-2131.
National Research Council. (2004). In Blank, M.R., Dabady, M., \& Citro, C.F., (Eds.). Measuring racial discrimination. Panel on methods for assessing discrimination. Washington, DC: The National Academies Press.

Nazroo, J. Y. (2003). The structuring of ethnic inequalities in health: Economic position, racial discrimination, and racism. American Journal of Public Health, 93(2), 277-284.

Noh, S., \& Kaspar, V. (2003). Perceived discrimination and depression: Moderating effects of coping, acculturation, and ethnic support. American Journal of Public Health, 93(2), 232-238.

Reid, P., \& Cram, F. (2005). Connecting health, people, and country in Aotearoa New Zealand. In K. Dew, \& P. Davis (Eds.), Health and society in Aotearoa New Zealand (2nd ed.) (pp. 33-48). Auckland: Oxford University Press.

Reid, P., \& Robson, B. (2006). The state of Maori health. In M. Mulholland \& contributors (Eds.), State of the Maori Nation: Twenty-first-century issues in Aotearoa (pp. 17-31). Auckland: Reed Books.

Roberts, R. K., Swanson, N. G., \& Murphy, L. R. (2004). Discrimination and occupational mental health services. Journal of Mental Health, 13(2), 129-142.

Salmond, C., \& Crampton, P. (2002). NZDep2001 Index of Deprivation. Wellington: Department of Public Health, Wellington School of Medicine and Health Sciences.

Spoonley, P. (1993). Racism and ethnicity (2nd ed.). Auckland: Oxford University Press.

Statistics New Zealand. (2001). 2001 Census of population and dwellings: Definitions and questionnaires. Wellington: Statistics New Zealand.

Statistics New Zealand. (2002). 2001 Census of population and dwellings: National summary. Wellington: Statistics New Zealand.

Statistics New Zealand. (2004). New Zealand life tables 2000-2002. Wellington: Statistics New Zealand.

Statistics New Zealand \& Ministry of Pacific Island Affairs. (2002). Pacific progress: A report on the economic status of Pacific peoples in New Zealand. Wellington: Statistics New Zealand.

Steffen, P. R., McNeilly, M., Anderson, N., \& Sherwood, A. (2003). Effects of perceived racism and anger inhibition on ambulatory blood pressure in African Americans. Psychosomatic Medicine, 65, 746-750.

Taylor, D. M., Wright, S. C., Maghaddam, F. M., \& Lalonde, R. N. (1990). The personal/group discrimination discrepancy: Perceiving my group, but not myself, to be a target of discrimination. Personality and Social Psychology Bulletin, 16, 254-262.

Verkuyten, M. (1998). Perceived discrimination and self-esteem among ethnic minority adolescents. Journal of Social Psychology, 138, 479-493.

Virdee, S. (1997). Racial Harassment. In T. Modood, R. Berthoud, J. Lakey, J. Nazroo, P. Smith, S. Virdee, \& S. Beishon (Eds.), Ethnic minorities in Britain: Diversity and disadvantage (pp. 259-289). London: Policy Studies Institute.

Ware, J. E., Kosinski, M., \& Gandek, B. (1993). SF-36 Health survey: Manual \& interpretation guide. Lincoln, RI: QualityMetric Incorporated.

Wiking, E., Johansson, S. E., \& Sundquist, J. (2004). Ethnicity, acculturation, and self reported health. A population based study among immigrants from Poland, Turkey, and Iran in 
Sweden. Journal of Epidemiology and Community Health, 58(7), 574-582.

Williams, D. R. (1997). Race and health: Basic questions, emerging directions. Annals of Epidemiology, 7(5), 322-333.

Williams, D. R., \& Collins, C. A. (2001). Racial residential segregation: A fundamental cause of racial disparities in health. Public Health Reports, 116, 404-416.
Williams, D. R., Neighbors, H. W., \& Jackson, J. S. (2003). Racial/ethnic discrimination and health: Findings from community studies. American Journal of Public Health, 93(2), 200-208.

Williams, D. R., \& Williams-Morris, R. (2000). Racism and mental health: The African American experience. Ethnicity and Health, 5, 243-268. 